\title{
Desenvolvendo a percepção musical em crianças através de um objeto de aprendizagem
}

\author{
Elieser Ademir de Jesus1 \\ Mônica Zewe Uriarte2 \\ André Luís Alice Raabe1,3 \\ \{elieser, uriarte, raabe\}@univali.br \\ 1Ciência da Computação \\ 2Licenciatura em Música \\ 3Mestrado em Computação Aplicada \\ Universidade do Vale do Itajaí - UNIVALI
}

\section{Resumo}

O desenvolvimento da percepção auditiva é um dos pilares da construção do conhecimento musical. Existe uma relação direta entre a qualidade do ambiente musical vivenciado na infância e a capacidade de um indivíduo adulto de entender os elementos da música. Este trabalho busca propor uma alternativa para auxiliar no desenvolvimento da percepção musical na Educação Infantil, focalizando especificamente crianças da faixa etária de 4 a 6 anos. Os poucos softwares desenvolvidos para Educação Musical utilizam geralmente uma abordagem pedagógica instrucionista, atribuindo pouca importância à questão do "aprender fazendo". Freqüentemente estes softwares disponibilizam sons de instrumentos musicais com baixa fidelidade, sendo esta uma estratégia questionável quando se trata da formação das referências sonoro-musicais de uma criança. Este artigo relata a construção de um objeto de aprendizagem, voltado à Educação Musical, concebido e construído tendo como principal objetivo ensinar elementos da música através da experimentação possibilitando às crianças a reflexão e construção de seus conhecimentos musicais.

Palavras-chave: Objeto de aprendizagem, construtivismo, educação musical, informática na educação.

\section{Developing children's musical perception through a learning object}

\begin{abstract}
The auditory perception development is the basis of musical knowledge construction. There is a direct relation between musical environment lived in the infancy and the capacity of an adult to understand the elements of the music. This paper proposes an alternative to aid the musical perception development in children education focusing specially on children from 4 to 6 years old. The few software developed for musical education, generally use a behaviorist approach that attributes little importance to the question of "learning making". Frequently these software provide low fidelity of the musical instruments sound, a questionable strategy when dealing with the formation of good musical references of a child. This paper describes the construction of a learning object to musical education conceived and constructed having as main objective to teach some elements of music through the experimentation allowing children to reflect and construct her musical nowledge.
\end{abstract}

Keywords: Learning objects, musical education, computer aided education. 


\section{Introdução}

A qualidade do ambiente musical vivenciado na infância está intimamente relacionada com a aptidão musical de um indivíduo. Sabe-se que crianças auditivamente pouco estimuladas provavelmente não desenvolverão com plenitude seu potencial musical.

Segundo o RCNEI - Referencial Curricular Nacional para a Educação Infantil (BRASIL, 1998), os estímulos musicais vivenciados durante a infância terão um impacto significativo na capacidade de um indivíduo de entender a música.

Gordon (2000) afirma que uma criança nasce com um determinado nível de aptidão musical e esse nível muda de acordo com a qualidade do seu ambiente musical, formal e informal, até a criança atingir os nove anos de idade.

Desde os primeiros momentos da vida as crianças demonstram interesse e curiosidade pelos sons. Segundo o RCNEI (BRASIL, 1998), do primeiro ao terceiro ano de vida, as crianças conferem importância e equivalência a toda e qualquer fonte sonora e estão sempre atentas às características dos sons ouvidos ou produzidos, descobrindo possibilidades sonoras com todo material acessível.

Além da curiosidade pelos sons também é notável o interesse das crianças pelo computador. Para Martins (1998), o computador é uma máquina que, se inserida num ambiente de experimentação, pode possibilitar ao indivíduo "dar formas às suas idéias", analisá-las e modificá-las e, em decorrência desse processo, construir conhecimento sobre o domínio musical.

Entretanto, segundo Miletto et al (2004), pouco software é desenvolvido especialmente para a educação musical e são poucos os pesquisadores de Informática na Educação que abordam questões desta área. Pesquisas têm sido realizadas no sentido de aplicar recursos tecnológicos à área musical, porém, apenas um pequeno número destas destina-se à educação, podendo ser utilizadas pelo professor de música no seu dia-a-dia.

Atualmente, uma abordagem para a construção de material instrucional denominada, por alguns, de objeto de aprendizagem vem ganhando destaque entre os pesquisadores de metodologias educacionais. Segundo Ferreira (2004), o conceito dos objetos de aprendizagem tem se mostrado forte candidato a liderar as alternativas de escolha para a área da educação devido ao seu potencial de reusabilidade, generalidade, adaptabilidade e escalabilidade.

O termo "objeto de aprendizagem" não é um consenso e Gibbons (2002 apud TORI, 2003), afirma que o conceito de objeto de aprendizagem vem recebendo diversas denominações, tais como "objeto de instrução", "objeto educacional", "objeto de conhecimento", "objeto inteligente", e "objeto de dados". Entretanto, segundo Tori (2003), independentemente da denominação empregada, o objetivo praticamente não varia e consiste em facilitar a decomposição de sistemas educacionais em módulos relativamente pequenos e potencialmente reutilizáveis. Wiley (2000) sustenta o mesmo conceito ao afirmar que a idéia fundamental dos objetos de aprendizagem consiste em permitir que os desenvolvedores de materiais instrucionais possam construir pequenos componentes (se comparados com o tamanho de todo um curso) reutilizáveis em diferentes contextos.

O presente artigo relata o processo de construção de um objeto de aprendizagem para o auxílio do desenvolvimento da percepção musical na Educação Infantil, em crianças de 4 a 6 anos. O objeto, chamado Zorelha, foi construído com o objetivo de permitir que as crianças possam realizar experimentações em contextos sonoros diversificados, utilizando o computador como ferramenta para a descoberta e construção de conhecimentos musicais.

\section{O Zorelha}


O principal objetivo do Zorelha é possibilitar a construção dos conhecimentos musicais através do desenvolvimento da percepção auditiva das crianças, permitindo que elas mesmas investiguem e descubram as muitas possibilidades do fazer musical.

Em geral, os softwares desenvolvidos para a educação musical tratam do ensino de música de uma forma conservadora, apresentando conteúdos musicais em uma ordem prédeterminada e com pouco, ou nenhum, estímulo auditivo. Alguns destes softwares são construídos segundo a visão de que, no ensino de música, o mais importante é o conhecimento da teoria musical (nomes das notas musicais, acordes, intervalos, escalas, ritmos, etc.), deixando de lado questões como o estímulo da audição e a importância da vivência e do contato com experiências musicais diversificadas. Segundo Martins (1998), a idéia de "aprender fazendo" já existe em algumas propostas educacionais em música, porém tem sido restringida pelas poucas "possibilidades do fazer" disponíveis.

O Zorelha aborda o ensino de música de uma maneira bastante informal e não possui atividades que envolvam, por exemplo, notação musical ou quaisquer outras formalidades simbólicas. Shafer (1992), um grande entusiasta de propostas construtivistas de ensino musical, diz que sempre resistiu ao ensino da leitura musical nos primeiros estágios da educação porque ela incita muito facilmente a um desvio da atenção para o papel e para o quadro negro, e estes não são os sons.

O Zorelha foi concebido e construído com base nas idéias do "aprender fazendo", e no caso específico da educação musical, o "aprender ouvindo", de forma que se possa aprender música através da música. Apesar da aparente redundância destas palavras, convém aqui ressaltar que, em geral, os softwares voltados à educação musical estimulam muito mais a visão - através de textos, imagens e animações - do que a audição, sendo esta última a grande responsável pela percepção, capacidade de apreciação e entendimento dos elementos constituintes da música.

O Zorelha não apresenta nenhum conceito musical (timbre, intensidade, melodia, compasso, etc.) de forma explícita através de textos ou falas explicativas.

Acreditamos que através da experimentação musical a criança pode elaborar e testar as suas próprias hipóteses sobre os elementos da música e então construir ela mesma os conceitos musicais mais elementares.

As atividades disponíveis no Zorelha podem ser utilizadas pela criança na ordem em que ela desejar. Não existe uma sequência de atividades pré-planejada, característica frequentemente encontrada em softwares similares. A qualquer momento a criança pode interagir com o software e experimentar qualquer uma das atividades disponíveis.

O Zorelha não trabalha com a idéia de "quantidade" de conhecimento musical e, por este motivo, não existem testes ou quaisquer outras tentivas de medição de conhecimento. Não é necessário, por exemplo, adquirir uma determinada quantidade de conhecimento musical para, a partir disto, ter acesso a uma nova atividade do Zorelha.

As atividades disponibilizadas no Zorelha não apresentam níveis de dificuldade progressivos, aspecto que também pode ser encontrado em softwares similares. Uma vez que não existem medições ou testes sobre o nível de conhecimento musical da criança não há porque existirem níveis de dificuldade nas atividades. Uma vez que todas as atividades do Zorelha baseiam-se na oportunização de experiências musicais, não há porque, e talvez nem como, medir ou julgar a qualidade da experimentação realizada por uma criança. Uma experimentação musical, no contexto do Zorelha, não pode ser boa ou ruim, adequada ou inadequada; ela será apenas uma experimentação, sem nenhum rótulo ou julgamento associado.

\subsection{Busca pela fidelidade sonora}


Utilizar arquivos de áudio com alta fidelidade no Zorelha implica em impor ao usuário maiores tempos de download, uma vez que o software foi projetado para ser utilizado em navegadores de internet.

Em softwares projetados para a internet a solução tradicional para redução do tamanho dos arquivos de áudio, e consequentemente o tempo de download, é adotar o formato MIDI (Musical Instrument Digital Interface). Alguns dos softwares voltados ao ensino de música (HARMONICVISION, 2007; METRONIMO, 2007) utilizam este padrão para gerar os sons dos instrumentos musicais. Segundo Paula Filho (2000), o tamanho dos arquivos MIDI é significativamente menor que dos arquivos de áudio.

Porém, se por um lado os arquivos MIDI são pequenos e possibilitam rápidas transferências pela internet, por outro, não há como garantir que o usuário vá ouvir sons de alta fidelidade no seu computador, sendo este um fator proibitivo para o uso do MIDI quando se trata de oferecer boas referências dos sons dos instrumentos musicais.

Segundo Vaughan (1994), um arquivo MIDI contém apenas instruções numéricas (qual nota tocar, quando tocar, com qual intensidade, por quanto tempo, com qual instrumento, etc.) que serão interpretadas e executadas por um sintetizador, sendo este último o principal responsável pela qualidade e fidelidade dos sons dos instrumentos musicais.

O padrão MIDI pode produzir bons resultados se for utilizado em conjunto com um sintetizador de qualidade. Porém, normalmente os usuários - no caso do Zorelha os alunos de escolas que posuam computadores equipados com multimídia - dispõem apenas do sintetizador embutido na própria placa de som do computador que, em geral, produz sons de baixa fidelidade. Uma música MIDI executada num sampler ou sintetizador profissional poderia ter uma fidelidade sonora muitas vezes superior em relação à fidelidade da mesma música executada com o sintetizador embutido na placa de som.

Buscando um alto nível de fidelidade sonora, os sons dos instrumentos musicais utilizados no Zorelha foram, a princípio, gravados no formato wave. Este formato é muito utilizado na digitalização de sons, pois possui uma alta qualidade em relação a outros formatos. Entretanto, os arquivos wave são inadequados para transmissão de áudio via internet, uma vez que acarretam, devido ao seu grande tamanho, downloads demasiadamente demorados.

Paula Filho (2000) afirma que alguns minutos de música podem ser gravados em um arquivo MIDI com algumas dezenas de kilobytes, enquanto um minuto de música gravada no formato wave com qualidade de CD corresponde a cerca de 10 megabytes.

Com o intuíto de minimizar o tempo de download necessário para a utilização do Zorelha e, com isto, melhorar a experiência dos usuários algumas técnicas foram utilizadas para reduzir o tamanho dos arquivos de áudio.

Os arquivos wave contendo os sons utilizados no Zorelha foram gravados no formato mono, pois, o som estéreo requer duas vezes mais espaço de armazenamento e tempo de download. Com isso, perde-se um pouco da qualidade sonora no que se refere à percepção espacial do som. Entretanto, julgou-se vantajoso o custo-benefício de se trabalhar com arquivos de áudio mono, uma vez que perde-se pouco na qualidade sonora e reduz-se pela metade o tamanho original dos arquivos de áudio.

Além do formato de áudio mono, os arquivos foram compactados usando MP3. Segundo Paula Filho (2000), arquivos com extensão mp3, ou arquivos MPEG Layer III, são arquivos de áudio semelhantes aos arquivos wave, porém extremamente compactados e com boa qualidade sonora.

Devido ao uso das técnicas citadas anteriormente as músicas di ponibilizadas do Zorelha - cada uma contendo sons de cinco instrumentos musicais diferentes - puderam ser armazenadas em arquivos compartilhados (ver bibliotecas compartilhadas na seção 2.3) com tamanho médio de 350 kilobytes por música. 


\subsection{O repertório utilizado no Zorelha}

O Zorelha disponibiliza músicas arranjadas em estilos musicais característicos de alguns países e culturas. Segundo Krüger et al (2003), o objetivo primeiro da educação musical é facilitar o acesso à multiplicidade de manifestações musicais da nossa cultura, bem como possibilitar a compreensão de manifestações musicais de culturas mais distantes.

As músicas utilizadas na ferramenta são músicas folclóricas infantis executadas com as "roupagens" dos estilos musicais que predominam no cotidiano das crianças em programas de TV, filmes, desenhos animados, jogos eletrônicos, etc. Entretanto, não foram utilizadas as letras das músicas e todos os arranjos foram feitos seguindo a abordagem de "música instrumental".

No RCNEI (BRASIL, 1998), observa-se a importância de se apresentar às crianças canções do cancioneiro popular infantil, da música popular brasileira, entre outras que possam ser cantadas sem esforço vocal. O mesmo documento ainda ressalta a importância de se oferecer à criança a oportunidade de ouvir música sem texto, uma vez que este tipo de música remete, sempre, ao conteúdo da letra, enquanto o contato com a música instrumental ou vocal sem um texto definido abre a possibilidade de se trabalhar a musica de outras maneiras.

\subsection{Ferramentas Utilizadas}

No que se refere à implementação, o Zorelha foi construído com a ferramenta Adobe Flash. O Flash foi escolhido pela facilidade de manipulação dos arquivos de mídia, e pela necessidade de sincronização entre vários sons simultâneos. Foi utilizada a versão 2.0 da linguagem ActionScript por esta fornecer os recursos necessários para a programação orientada a objetos, paradigma de programação utilizado no Zorelha.

Uma característica do Flash que foi fundamenta na construção do Zorelha é o recurso das bibliotecas compartilhadas (Shared Libraries). Elas permitem que múltiplos filmes compartilhem informações como movie clips, botões, gráficos e sons.

Por exemplo, uma biblioteca compartilhada (um filme do Flash contendo itens reutilizáveis) pode conter vários sons que são utilizados em diferentes filmes do Flash.

Uma vez que a biblioteca que contém os sons compartilhados tenha sido descarregada pelo browser os items da biblioteca estarão acessíveis para qualquer outro filme, sem a necessidade de novos downloads.

O zorelha utilizou o recurso de bibliotecas compartilhadas para disponibilizar os sons das músicas em todas as atividades (descritas na seção 2.4), pois estas são baseadas nas mesmas músicas, ou seja, a criança pode realizar tarefas distintas com a mesma música. Sem o recurso das bibliotecas compartilhadas haveria muita redundância nos arquivos de mídia e consequentemente seria necessário maior espaço de armazenamento e tempo de download, uma vez que cada uma das atividades do Zorelha precisaria armazenar uma cópia dos sons dos instrumentos que executam as músicas.

Para os arranjos e gravações das músicas utilizou-se o software Cakewalk Sonar, um software sequenciador que permite a gravação, execução e edição de múltiplas trilhas (tracks) de áudio e/ou MIDI.

Em um primeiro momento, as músicas do Zorelha foram gravadas em MIDI (sequenciadas), com exceção dos sons de guitarra que foram gravados diretamente em áudio. As gravações MIDI foram transformadas em arquivos de áudio no formato wave através da gravação dos sons gerados por softwares sintetizadores chamados instrumento virtuais. Estes softwares, quando acionados com mensagens MIDI (instrucões computacionais que indicam qual nota deve ser tocada, com qual intensidade, em que momento, etc), "imitam" o som dos instrumentos reproduzindo gravações de sons de instrumentos musicais reais, são chamados de samplers. 
Finalmente, os arquivos wave obtidos no processo descrito anteriormente foram importados para o Flash e então compactados em MP3, o formato de áudio utilizado no Zorelha.

\subsection{Atividades disponíveis no Zorelha}

O Zorelha foi dividido em módulos, sendo que cada módulo representa uma atividade, a saber: módulo Show, módulo Mixer e módulo Jogo.

$\mathrm{O}$ acesso aos módulos do Zorelha é feito através de uma tela inical onde a criança pode escolher qual dos módulos deseja utilizar (Figura 1). Todas as telas do Zorelha, com exceção apenas da tela inicial, disponibilizam um botão que direciona o usuário para a tela de acesso aos módulos. Este botão - a imagem de uma mão apontando para o lado esquerdo - pode ser observado no canto inferior esquerdo da figura 2. No lado inferior direito da mesma figura pode-se observar os botões que permitem a escolha das músicas do Zorelha. Pode-se observar a imagem de um soldado e de um gato representando respectivamente as músicas infantis "Marcha soldado" e "Atirei o pau no gato".

Em todas as atividades do Zorelha os instrumentos que executam a música escolhida pela criança soam de forma sincronizada entre si, ou seja, todos os instrumentos executam a mesma música ao mesmo tempo, com o mesmo rítmo e cadência musical, iniciando e terminando simultâneamente a execução da música.

Apesar destas características parecerem óbvias por serem especificidades da música já bem conhecidas, alguns softwares similares não observam estas questões e disponibilizam sons de diferentes instrumentos musicais, porém, cada instrumento executando uma música diferente e sem nenhuma preocupação com a sincronia musical.

Por se tratar de um software voltado para Educação Infantil, o Zorelha apresenta todas as instruções e demais diálogos através de falas, uma vez que a faixa etária estipulada para o software (crianças de 4 a 6 anos) não possui habilidade de leitura. As falas são apresentadas por uma personagem: A Professora do Zorelha. A imagem da personagem pode ser visualizada no canto inferior esquerdo da figura 1.

Todos os botões e demais objetos do Zorelha que permitem interação através do mouse estão associados a uma instrução falada. Assim, sempre que a criança repousa o mouse sobre um objeto interativo (botão, músico, etc) a personagem professora fornece uma explicação falada sobre o objeto apontado pelo mouse.

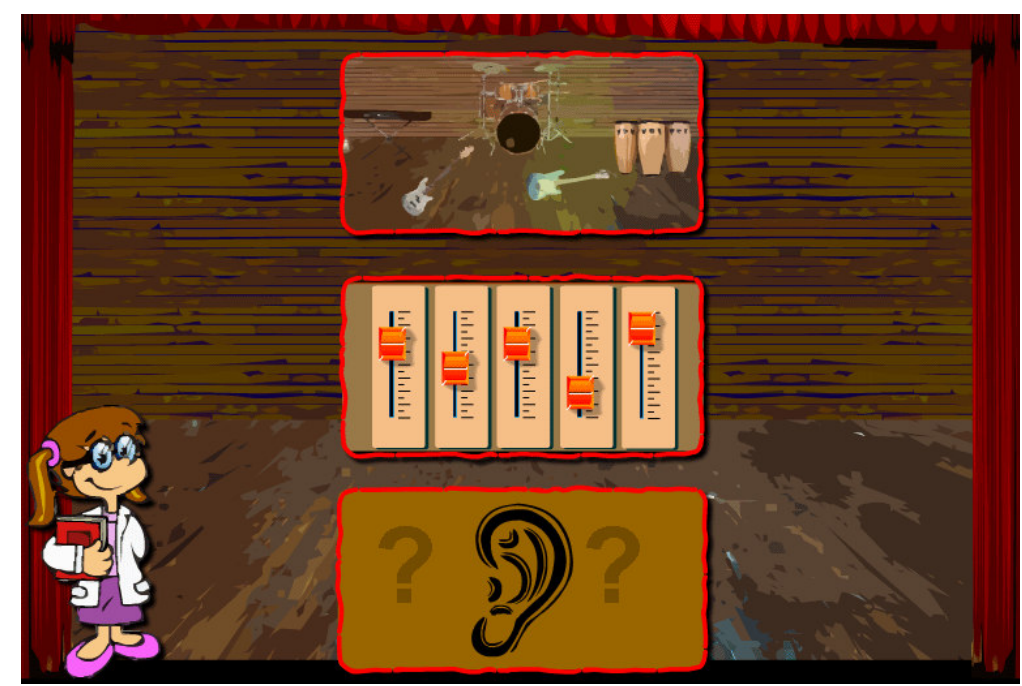

Figura 1 - A "Professora" do Zorelha e os botões de acesso aos módulos. 


\subsubsection{Módulo Show}

O objetivo deste módulo é permitir a livre experimentação através da combinação de sons de instrumentos musicais. A metáfora utilizada é um palco onde acontece um show de música, sendo que a criança decide quais instrumentos participam do show.

O Zorelha disponibiliza, para cada música, um conjunto de instrumentos musicais representados por músicos em miniatura na parte inferior da tela (figura 2).

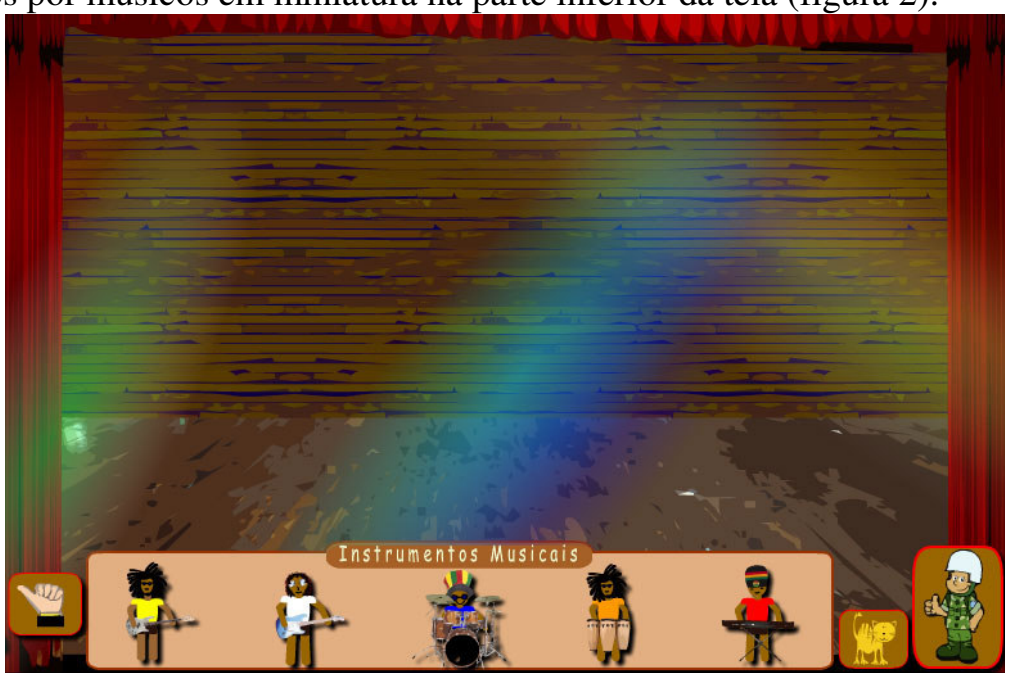

Figura 2 - Palco vazio, nenhum músico participando do show.

A criança escolhe quais os instrumentos musicais quer colocar no palco clicando nas miniaturas dos músicos. Ao clicar em uma das miniaturas, este músico vai para o palco e o som do seu instrumento pode ser ouvido. A qualquer momento a criança pode retirar o músico do palco clicando sobre ele e, em conseqüência disto, o som do instrumento do músico é silenciado e o mesmo volta para a parte inferior da tela. A figura 3 exemplifica visualmente a ação de colocar dois dos músicos no palco.

Utilizando-se de metáforas simples, como colocar e retirar os músicos do palco, a ferramenta Zorelha permite que a criança experimente todas as combinações sonoras possíveis dentro do conjunto de instrumentos musicais disponibilizados em uma música.

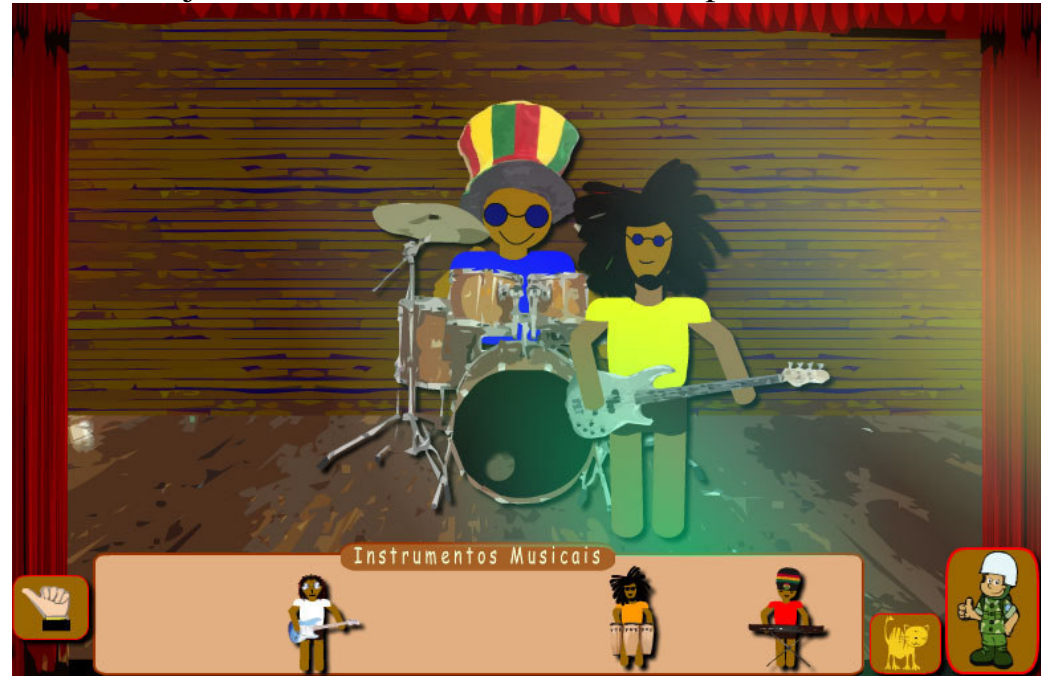

Figura 3 - Dois músicos no palco.

\subsubsection{Módulo Mixer}


O módulo Mixer tem como objetivo permitir que as crianças façam experimentações com a intensidade sonora (volume) e que percebam as diferenças entre as possíveis configurações nos volumes dos instrumentos musicais.

Neste módulo a criança pode controlar o volume de cada um dos instrumentos musicais através de um potenciômetro, utilizando a metáfora de uma mesa de som ou mixer (Figura 4). Cada um dos potenciômetros pode ser arrastado para cima ou para baixo com o mouse, aumentando ou diminuindo o volume do instrumento musical associado ao potenciômetro manipulado.

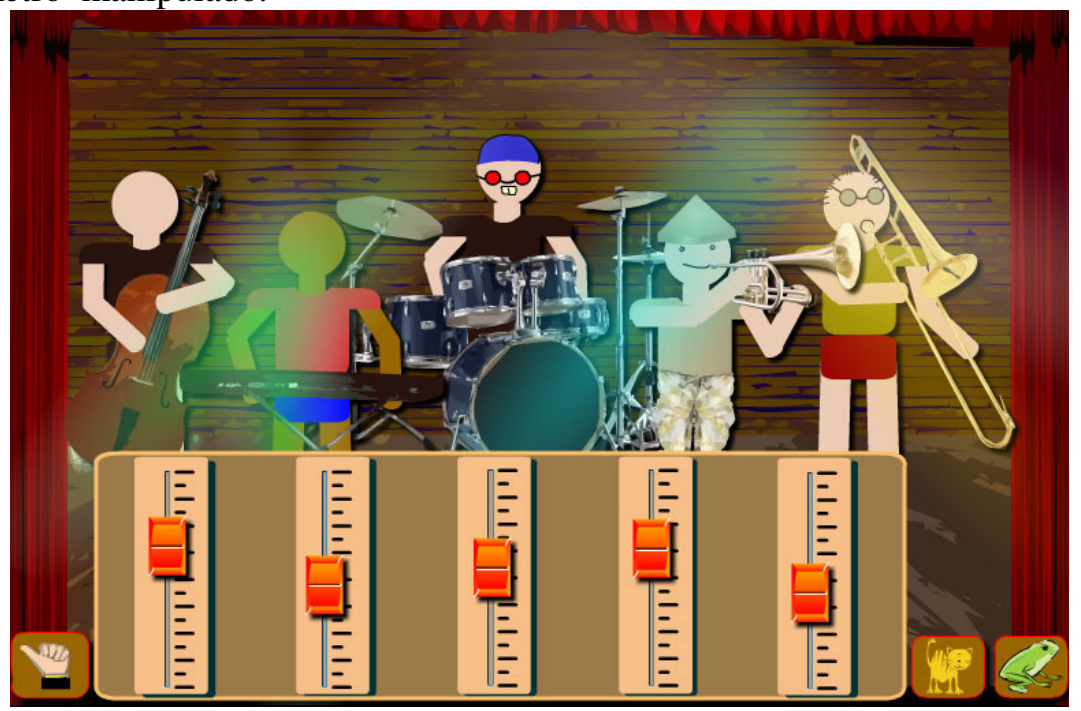

Figura 4 - Mesa de som (mixer) do Zorelha.

\subsubsection{Módulo Jogo}

O módulo Jogo tem como objetivo permitir que a criança descubra os timbres dos instrumentos musicais. O jogo começa com a criança escolhendo uma das músicas do Zorelha. Em seguida, com o palco vazio, um dos instrumentos que executam a música começa a ser executado e a criança deve colocar no palco o músico que toca o instrumento que está sendo ouvido. Quando a criança indica o músico correto, este vai para o palco e um novo instrumento começa a soar, porém, junto com o som do instrumento que foi colocado no palco anteriormente. Neste momento a criança deve identificar o novo instrumento que começou a tocar e também colocá-lo no palco. O jogo termina quando todos os instrumentos da música forem colocados no palco. O desafio do jogo vai aumentado na medida em que a criança vai indicando corretamente os instrumentos que está ouvindo, uma vez que com vários instrumentos tocando simultaneamente será mais difícil identificar o instrumento que começou a ser tocado por último.

\section{Resultados e Discussões}

Um experimento preliminar foi realizado com um aluno de educação musical infantil do Setor de Música de uma instituição de ensino superior. $\mathrm{O}$ aluno de 5 anos não possuía, na realização do teste, experiência em atividades semelhantes.

Verificou-se que, por não ter experiência com o uso do mouse, em alguns momentos o aluno não conseguiu colocar os músicos no palco, tarefa realizada com um clique do mouse. $\mathrm{O}$ aluno também demonstrou dificuldade para controlar os potenciômetros da mesa de som do módulo "Mixer", uma vez que não possuía a habilidade de "arrastar" com o mouse. 
Quando o aluno foi questionado sobre qual das "brincadeiras" experimentadas mais gostou ele indicou o módulo Show como sendo a brincadeira preferida. É possível que a dificuldade de uso do módulo Mixer e a maior facilidade encontrada pelo aluno no módulo Show tenham influenciado esta decisão. Entretanto, qualquer afirmação nesse sentido seria falaciosa, uma vez que estudos mais consistentes ainda não foram realizados.

Apesar das dificuldades relacionadas ao uso do mouse o aluno demonstrou reações bastante positivas durante a utilização da ferramenta tais como movimentar o corpo no ritmo da música e cantar as melodias das músicas junto com software.

O aluno também conseguiu diferenciar os timbres dos instrumentos musicais.

Isto ficou caracterizado quando, a pedido da professora de música, o aluno identificou o instrumento que tocava a melodia, retirou este instrumento do palco (silenciando a melodia) e então cantou a melodia da música, acompanhado pelos outros instrumentos que estavam no palco do Zorelha. Neste momento, o Zorelha foi utilizado como um karaokê, uma possibilidade de uso do software até então não imaginada. Porém, cabe lembrar que em um karaokê "comum" não se tem a liberdade de construir e desconstruir o acompanhamento de uma música.

Dando continuidade ao desenvolvimento do Zorelha, pretende-se solucionar os problemas relacionados à dificuldade de uso e ampliar as funcionalidades da ferramenta.

Dentre as ampliações projetadas estão a inclusão de mais arranjos em estilos musicais diferentes para uma mesma música e a inclusão de um módulo chamado "Prática de conjunto", onde a criança poderá explorar as possibilidades dos instrumentos com o mouse. Além disso, estão planejadas melhorias na interface gráfica da ferramenta, a utilização da ActionScript 3.0 como linguagem de programação e a adequação do Zorelha ao padrão SCORM (Sharable Content Object Reference Model), um conjunto unificado de padrões e especificações para conteúdo, tecnologias e serviços para elearning.

Também estão planejados experimentos com uma amostra mais significativa e heterogênea em relação à faixa etária e experiência com o uso do computador.

\section{Referências Bibliográficas}

BRASIL. Referencial Curricular Nacional para a Educação Infantil, Ministério da

Educação e do Desporto. Secretaria de Educação Fundamental.. Brasília: MEC/SEF,

1998. v.1, v.3.

BRITO, T. A. Música na educação infantil: propostas para a formação integral da criança. 2. ed. São Paulo: Peirópolis, 2003.

FERREIRA, L. F. Usando Objetos Educacionais baseados em Realidade Virtual em ambientes de apoio a construção de conhecimento e aprendizagem de técnicas videocirúrgicas. RENOTE - Revista Novas Tecnologia na Educação, V.2, N.1, Março,

2004.

GORDON, E. Teoria de aprendizagem musical: competências, conteúdos e padrões.

Lisboa: Fundação Calouste Gulbenkian, 2000. HARMONICVISION. Music Ace 2. Disponível em: <http://www.harmonicvision.com/>. Acesso em: 20 maio 2007. 
KRÜGER et al. Dos receios à exploração das possibilidades: formas de uso de software educativo-musical. In: HENTSCHKE, L.; DEL BEM, L. Ensino de Música: propostas para pensar e agir em sala de aula, 2003.

MARTINS, M. C. O fazer musical em um contexto computacional. In: VALENTE J.

A. Computadores e conhecimento: repensando a educação, Campinas: Unicamp/NIEP, 1998.

METRONIMO. Metronimo. Disponível em: <http://www.metronimo.com/>. Acesso em: 20 maio 2007.

MILETTO, E. M.; COSTALONGA, L. L.; FLORES, L. V.; FRITSCH, E. F.;

PIMENTA, M. S.; VICARI, R. M. Educação Musical auxilicada por computador:

Algumas Consideraçõs e Experiências. RENOTE - Revista Novas Tecnologia na Educação, V.2, N.1, Março, 2004.

PAULA FILHO, W. P. Multimídia: Conceitos e aplicacoes. Rio de Janeiro: LTC, c 2000

SCHAFER, R. M. O ouvido pensante. São Paulo: Universidade do Estado de São Paulo, 1992.

TORI, R. O Virtual que Marca Presença. Revista Brasileira de Aprendizagem Aberta e a Distância, v. 2, n. 1, 2003.

VAUGHAN, T. Multimidia na pratica. Sao Paulo: Makron, 1994.

WILEY, D. A. Learning object design and sequencing theory. 2000. $142 \mathrm{f}$.

Dissertação (Doutorado em Filosofia) - Department of Instructional Psychology and Technology Brigham Young University, 2000. 